\title{
Association of PCK1 with Body Mass Index and other metabolic features in patients
}

\section{with psychotropic treatments.}

Núria Saigi-Morgui, PharmD, MPH (1); Frederik Vandenberghe, PharmD, MSc (1); Aurélie Delacrétaz,

MSc (1); Lina Quteineh, MD PhD (1); Eva Choong, PhD (1); Mehdi Gholamrezaee, PhD (2); Pierre

Magistretti, MD, PhD (3,4); Jean-Michel Aubry, MD (5); Armin von Gunten, MPhil, MD; (6) Martin Preisig

MD, MPH (2); Enrique Castelao, MSc (2); Peter Vollenweider, MD (7); Gerard Waeber, MD (7); Zoltán

Kutalik, PhD (8, 9); Philippe Conus, MD (10); Chin B Eap, PhD $(1,11)$

1 Unit of Pharmacogenetics and Clinical Psychopharmacology, Centre for Psychiatric Neuroscience,

Department of Psychiatry, Lausanne University Hospital, Prilly, Switzerland.

${ }^{2}$ Centre of Psychiatric Epidemiology and Psychopathology, Department of Psychiatry, Lausanne

University Hospital, Prilly, Switzerland.

${ }^{3}$ Centre for Psychiatric Neuroscience, Department of Psychiatry, Lausanne University Hospital, Prilly,

Switzerland.

${ }^{4}$ Laboratory of Neuroenergetics and Cellular Dynamics, Brain Mind Institute, Ecole Polytechnique

Fédérale de Lausanne, Lausanne, Switzerland.

${ }^{5}$ Department of Mental Health and Psychiatry, University Hospital of Geneva, Geneva, Switzerland. 
${ }^{6}$ Service of Old Age Psychiatry, Department of Psychiatry, Lausanne University Hospital, Prilly

Switzerland.

${ }^{7}$ Department of Medicine, Lausanne University Hospital, Lausanne, Switzerland.

8 Institute of Social and Preventive Medicine (IUMSP), Lausanne University Hospital,

Lausanne, Switzerland.

${ }^{9}$ Swiss Institute of Bioinformatics, Lausanne, Switzerland.

10 Service of General Psychiatry, Department of Psychiatry, Lausanne University Hospital, Prilly

Switzerland.

11 School of Pharmaceutical Sciences, University of Geneva, University of Lausanne, Geneva,

Switzerland. 


\section{Funding}

2 This work has been funded in part by the Swiss National Research Foundation (CBE and PC: 320030-

3120686 and 324730_144064). PV and GW received an unrestricted grant form GlaxoSmithKline to build

4 the CoLaus study. The CoLaus/PsyCoLaus study is supported by financial contributions from

5 GlaxoSmithKline, the Faculty of Biology and Medicine of Lausanne, the Swiss National Science

6 Foundation (grants 3200B0-105993, 3200B0-118308, 33CSCO-122661, 33CS30-139468 and 33CS30-

7 148401)). ZK received support from the Leenaards Foundation and the Swiss National Science

8 Foundation (31003A-143914). The funding sources had no role in the writing of the manuscript or in the

9 decision to submit it for publication.

\section{Author disclosure information}

11 CBE received research support from Takeda and from the Roche Organ Transplantation Research

12 Foundation in the past 3 years. He received honoraria for conferences or teaching CME courses from

13 Advisis, Astra Zeneca, Janssen-Cilag, Lundbeck, Merck Sharp \& Dohme, Otsuka, Sandoz, Servier and

14 Vifor-Pharma in the past 3 years. AVG received honoraria for a conference or a workshop participation

15 from Vifor and Bayer Sheringer in the past 3 years. All authors declare no conflict of interest in relation to

16 the content of the paper. 
Weight gain is a major health problem among psychiatric populations. It implicates several receptors and

20 hormones involved in energy balance and metabolism. Phosphoenolpyruvate carboxykinase 1 (PCK1) is

21 a rate-controlling enzyme involved in gluconeogenesis, glyceroneogenesis and cataplerosis and has

22 been related to obesity and diabetes phenotypes in animals and humans. The aim of this study was to

23 investigate the association of $P C K 1$ polymorphisms with metabolic traits in psychiatric patients treated

24 with psychotropic drugs inducing weight gain and in general population samples. One polymorphism

25 (rs11552145G>A) significantly associated with Body Mass Index in the psychiatric discovery sample

$26(\mathrm{n}=478)$ was replicated in 2 other psychiatric samples $\left(\mathrm{n}_{1}=168, \mathrm{n}_{2}=188\right)$, with $A A$-genotype carriers having

27 lower Body Mass Index as compared to G-allele carriers. Stronger associations were found among women younger than 45 years carrying $A A$-genotype as compared to G-allele carriers $\left(-2.25 \mathrm{~kg} / \mathrm{m}^{2}\right.$,

$29 \mathrm{n}=151, \mathrm{p}=0.009)$ and in the discovery sample $\left(-2.20 \mathrm{~kg} / \mathrm{m}^{2}, \mathrm{n}=423, \mathrm{p}=0.0004\right)$. In the discovery sample for

30 which metabolic parameters were available, $A A$-genotype showed lower waist circumference $(-6.86 \mathrm{~cm}$,

$31 \mathrm{p}=0.008)$ and triglycerides levels $(-5.58 \mathrm{mg} / 100 \mathrm{~mL}, \mathrm{p}<0.002)$ when compared to $G$-allele carriers. Finally,

32 waist to hip ratio was associated with $r s 6070157$ (proxy of $r s 11552145, r^{2}=0.99$ ) in a population-based sample $\left(\mathrm{N}=123^{\prime} 865, \mathrm{p}=0.022\right)$. Our results suggest an association of $r s 11552145 G>A$ polymorphism with 


\section{INTRODUCTION}

36 Weight gain is a known side-effect of psychotropic drugs such as antipsychotics, mood stabilizers and

37 antidepressants. ${ }^{1}$ Psychotropic-induced weight gain can lead to many metabolic complications (e.g.

38 increase in triglycerides, cholesterol, waist circumference) and is related to comorbidities such as

39 diabetes, hypertension and other cardiovascular diseases. ${ }^{2}$ Psychiatric populations have a 10 to 25 year

40 reduction in life expectancy due to comorbidities and to the psychiatric illness itself, corresponding to a 2-

413 fold increased mortality rate when compared to healthy populations. ${ }^{3}$ Obesity is attributed to the

42 psychiatric illness, to behavioral and environmental factors (i.e. diet, exercise, smoking), as well as

43 genetic factors. ${ }^{4}$ Besides, an interaction between genetic factors and psychotropic drug inducing weight

44 gain has been described implicating several receptors (e.g. serotonin and dopamine receptors) and

45 hormones (e.g. leptin) involved in energy balance or metabolism pathways. ${ }^{5,6}$

46 The Phosphoenolpyruvate carboxykinase (PCK) gene codes for an enzyme involved in the

47 gluconeogenesis ${ }^{7}$ and is found in two forms, PCK1 (cytosolic) and PCK2 (mitochondrial). Both enzymes

48 are expressed equally in the liver but their expression may vary depending on the tissue. ${ }^{7,} 8$ PCK

49 catalyzes the conversion from oxalacetate into phosphoenolpyruvate (a rate-controlling step of

50 gluconeogenesis) and is also involved in glyceroneogenesis and cataplerosis. ${ }^{7}$ Of note, $P C K$ is a

51 downstream gene of the CREB-regulated transcription coactivator 1 (CRTC1) which is implicated in

52 hypothalamic control of food intake 9,10 and we recently found in general and psychiatric populations that 
53 carriers of a variant allele of a CRTC1 polymorphism appear to be protected against weight gain

54 especially in women younger than 45 years old. ${ }^{11}$

55 Rodents who over-express $P C K 1$ and $P C K 2$ were obese, hyperglycemic and insulin resistant ${ }^{12,} 13$

56 whereas mice that under-expressed PCK1 and PCK2 developed a lipodistrophy type of metabolic

57 syndrome. ${ }^{14}$ This is in line with the positive correlation found between PCK1 mRNA expression levels and

58 Body Mass Index (BMI), body fat percentage, triglycerides (TG) and cholesterol (CHOL) levels in

59 subcutaneous adipose tissue of non-menopausal women. ${ }^{15}$ In humans, regions near PCK1 locus have

60 been related to obesity or fat mass ${ }^{16,17}$ and several positive associations have been reported between

61 PCK1 polymorphisms and type 2 diabetes ${ }^{18-20}$ although these results could not always be replicated. ${ }^{21}$

62 Other studies conducted in the general population showed no significant association between PCK1

63 polymorphisms and BMI, waist circumference (WC) or physical activity. ${ }^{22}$ A case-control study in a

64 diabetic versus non diabetic population also found that non diabetic homozygous for the minor allele of a

65 PCK1 polymorphism $(+4824 T>C)$ had increased levels of high density lipoproteins (HDL) and lower TG

66 levels when compared to wild type. ${ }^{23}$ Thus growing evidence supports that PCK contributes to obesity

67 and metabolic syndrome in the general population but, to our knowledge, no studies have yet been

68 conducted in psychiatric populations which are at high risk for developing obesity and metabolic

69 syndrome. The aim of the present study was to analyze whether $P C K 1$ polymorphisms were associated

70 with $\mathrm{BMI}$ and other metabolic traits (i.e. WC, blood glucose levels (BGL), low density lipoprotein (LDL), 
$71 \mathrm{HDL}, \mathrm{CHOL}$ and TG in three independent psychiatric populations treated with drugs inducing weight gain

72 and in 3 large general population cohorts. As a secondary aim, we wanted to explore how PCK1 and

73 CRTC1 polymorphisms are associated with BMI in a combined analysis.

\section{MATERIALS AND METHODS}

75 Psychiatric sample description

76 The first psychiatric sample (discovery sample) was recruited during a longitudinal follow-up study on

77 metabolic syndrome at the Lausanne Psychiatric University Hospital (started in 2007, ongoing). 478

78 Caucasian patients switching or starting a treatment with drugs known to potentially induce weight gain

79 (aripiprazole, amisulpride, clozapine, olanzapine, quetiapine, risperidone, mirtazapine, lithium and/or

80 valproate) were included. Weight, height and other clinical variables were reported at baseline and at 1, 2,

$813,6,9$ and 12 months after starting the treatment according to published monitoring guidelines of weight

82 and metabolic syndrome parameters. ${ }^{24}$ Most patients had already received other psychotropic treatment

83 before the current treatment. Fasting BGL and lipid levels (i.e. CHOL, TG, LDL, HDL) were analyzed on a

84 routine basis on blood samples using a Modular P apparatus (Roche Diagnostics, Switzerland). For

85 patients for whom drug plasma determinations were available, we conducted preliminary analysis on the

86 influence of compliance on the observed associations. For this purpose, we defined an arbitrary threshold

87 at $10 \%$ of the minimal therapeutic drug plasma concentration ${ }^{25}$ (i.e. $2,35,10,2,15,10,2 \mathrm{ng} / \mathrm{mL}, 0.05$

$88 \mathrm{mmol} / \mathrm{L}, 5 \mathrm{mg} / \mathrm{L}$ for olanzapine, clozapine, quetiapine, risperidone + hydroxy-risperidone, aripiprazole, 
89 amisulpride, paliperidone, lithium, and valproate) to ensure psychotropic drug intake. Similar results to

90 those described in the present paper were obtained (data not shown). Thus, to increase the power of

91 the study, the whole cohort was used for statistical analysis. Two other psychiatric samples were used as

92 replication samples. A retrospective study (replication sample 1) was conducted in an outpatient setting in

93 Geneva University Hospital in 2007. 168 Caucasian patients treated for at least 3 months with

94 olanzapine, clozapine, quetiapine, risperidone, lithium and/or valproate were recruited. Another

95 retrospective outpatient study in Lausanne, replication sample 2 (started in 2010, ongoing) included 188

96 Caucasian patients mostly treated for more than one year with aripiprazole, amisulpride, clozapine,

97 olanzapine, quetiapine, risperidone, mirtazapine, lithium and/or valproate. For both replication samples,

98 questionnaires were filled during one of the patient routine follow-ups and weight, height, WC and

99 treatment duration were reported among other clinical variables. Weight before starting psychotropic

100 treatment was self-reported or extracted from medical files. As shown previously, ${ }^{11}$ self-reported weight

101 was found to be a reliable estimate of the measured weight extracted from medical files.

102 In all samples, patients with previous treatments were included after having switched medication. The

103 latest introduced psychotropic medication was considered as the main psychotropic treatment. Weight

104 (patients with light clothes and without shoes) was measured in kilograms to the nearest kg. Height was

105 measured using a height gauge to the nearest $\mathrm{cm}$. WC was measured to the nearest $\mathrm{cm}$. BMI for all

106 individuals was obtained by dividing weight (in $\mathrm{kg}$ ) by squared height (in $\mathrm{m}^{2}$ ). 
107 Written informed consent was provided by all individuals or by their legal representatives and the studies

108 were approved by the ethics committee of the corresponding centers. Further details of the 3 psychiatric

109 cohorts have already been described elsewhere. ${ }^{11,26}$ Of note, the present study refers to the same 3

110 psychiatric populations than in our previous paper, ${ }^{11}$ but with a larger number of patients included in the

111 discovery cohort and in the replication sample 2 (inclusions ongoing).

\section{Population-based samples}

113 Significant results were tested for replication in three population based samples: Participants in CoLaus

114 ( $n=5$ '338) were recruited between June 2003 and May 2006 in the Lausanne area as described

115 previously. ${ }^{27}$ The Genetic Investigation of Anthropometric Traits Consortium (GIANT) performed a meta-

116 analysis of genome-wide association study data with a discovery set of 123'865 individuals of European

117 ancestry from 46 studies for height, ${ }^{28} \mathrm{BMl},{ }^{4}$ and waist-to-hip ratio (WHR). ${ }^{29}$ Finally, the second set of

118 association summary statistics for general populations (Global Lipids Genetics Consortium) was

119 downloaded from "Genome Wide Associations Scans for Total Cholesterol, HDL-C, LDL-C and

120 triglycerides" website ${ }^{30}$ and contains data related to lipid traits $(n=100$ '184). Of note, CoLaus is part of

121 both GIANT and Global Lipids Genetics Consortium.

\section{SNP selection and Genotyping}


123 In a first step, the best replicated and studied $P C K 1$ polymorphism in the literature (i.e. rs2071023) was

124 manually genotyped using TaqMan allelic discrimination assay (ABI PRISM 7000 Sequence Detection

125 System; Applied Biosystems, Rotkreuz, Switzerland, TaqMan SNP genotyping assays ID: C_2508731_1).

126 Additionally, three SNPS which were available in the CardioMetaboChip were also considered for

127 analysis (i.e. rs11552145, rs707555 and rs8123020). The CardioMetaboChip is a custom Illumina iSelect

128 genotyping array designed to test DNA variation of 200 '000 SNPs from regions identified by large scale

129 meta-analyses of genome wide association studies (GWAS) for metabolic and cardiovascular traits.

130 Quality control excluded samples from the analysis if gender was inconsistent with genetic data from X-

131 linked markers, genotype call rate <0.96, Gene Call (GC) score $<0.15$. GenomeStudio Data Analysis

132 Software was used to export results generated by Illumina CardioMetaboChip. In total, four SNPs were

133 considered for analyses with minor allele frequency (MAF) higher than 0.10 (Table S-1). All of them were

134 in Hardy Weinberg Equilibrium (HWE) (Table S-2). Finally, looking at HapMap Genome Browser (release

135 27, MAF>0.10, cutoff of $r^{2}$ set at 0.8$),{ }^{31}$ we found that several $P C K 1$ tagging SNPs were in linkage

136 disequilibrium (LD) with our four selected SNPs (see details in Figure S-1).

137 DNA was extracted from blood samples as described by the manufacturer's protocol using Flexigene

138 DNA kit and QIAamp DNA Blood Mini QIAcube Kit (Qiagen AG, Switzerland) for 834 Caucasian patients

139 from the three psychiatric cohorts. Genotyping of the $r s 3746266 A>G$ SNP from CRTC1 was performed

140 using TaqMan allelic discrimination assay (ABI PRISM 7000 Sequence Detection System; Applied 
141 Biosystems, Rotkreuz, Switzerland) and according to the manufacturers protocol as described

142 elsewhere. ${ }^{11}$ Genotyping of the CoLaus subjects was performed using the Affymetrix GeneChip Human

143 Mapping 500K array set as previously described. ${ }^{27}$

\section{Variables of the study}

145 The main outcome analyzed in the three psychiatric samples was the BMI $\left[\mathrm{kg} / \mathrm{m}^{2}\right]$ used as a continuous

146 variable. Other outcomes studied were WC [cm], LDL, HDL, TG, CHOL and BGL [mg/100mL]. PCK1

147 genotypes were grouped and analyzed in recessive (for rs11552145, rs707555 and rs8123020) and

148 dominant (for rs2071023) models according to their association with BMI showed in preliminary analyses.

149 Other covariates were extracted from medical files or during the interview and included demographic data

150 (i.e. sex, age and ethnicity) as well as history of treatment (type of psychotropic drug and treatment

151 duration). In order to preserve homogeneity of the samples, only patients treated up to 24 months were

152 taken into account in combined (i.e discovery plus replication) psychiatric sample analyses.

\section{Statistical analysis}

154 Psychiatric Samples

155 HWE was determined for each polymorphism by a chi-square test. Statistical analyses were done using

156 STATA 12.1 (StataCorp, College Station TX, USA) and R version 2.11.1 software. ${ }^{32}$ P-values less than

1570.05 were considered as statistically significant and when necessary, Bonferroni correction for multiple 
158 tests was applied. Eventually, differences in sample size might be due to missing genotypes and/or 159 covariates. First, exploratory analyses were conducted to explore differences in BMI between genetic 160 groups in the three psychiatric samples using Mann-Whitney $U$ non parametric test. To fit a longitudinal 161 model on the BMI trend, due to complex and non-linear BMI evolution in time and presence of multiple

162 observations per individual which introduces interdependence among observations, a Generalized

163 Additive Mixed Model (GAMM) was used to assess the association of genetic polymorphism with BMI 164 adjusted by sex, age, treatment and treatment duration. This allowed a smooth trend for the response in 165 time based on multiple observations for each patient (using a thin plate regression spline basis). A 166 random effect at the subject level was also introduced to take the dependence structure of observed data

167 into account. ${ }^{33}$ The GAMMs were fitted using the mgcv package of $\mathrm{R}$ (settings were fixed at package

168 defaults). To be more conservative, the uncertainty of estimated parameters was assessed by 1 '000

169 bootstraps on individuals. For those p-values lower than $0.001,10$ '000 bootstraps were performed

170 whenever possible. Multivariate analysis used the same methodology as previously described for the

171 upstream CRTC1 gene:11 It was first conducted in the discovery sample and the significant results were

172 tested for replication in the two replication samples. In fitted longitudinal models, stratification by sex, and

173 in some cases by age, was applied when analyzing all samples together. Also, analyzes on WC and on

174 other metabolic traits (i.e. BGL and lipid levels) were conducted in the discovery sample (data available

175 only in this sample) and only for rs11552145 and rs2071023 polymorphisms. Due to some missing data

176 and the relatively low number of variant alleles of rs707555 and rs8123020, analysis could not be 
177 conducted for these polymorphisms. Finally it should be mentioned that preliminary analysis on PCK1

178 haplotypes and BMI for the 3 SNPs that formed a haplotype block (i.e. rs 11552145 , rs707555 and

179 rs8123020) showed no significant results (results not shown).

Population-Based Samples

181 Significant results from PCK1 polymorphisms in the discovery sample (i.e. rs6070157, proxy of

182 rs 11552145; $r^{2}=0.99$ and $\left.r s 2071023\right)$ were further tested for replication in the three population samples

183 (CoLaus, GIANT and Global Lipids Genetics Consortium).

184 The associations of PCK1 polymorphisms with adiposity markers such as BMI, WC, fat mass and lipid

185 factors were analyzed using multiple linear regression with additive model in which potential confounding

186 factors such as age, sex, and smoking status were added as covariates in the CoLaus study. For

187 anthropometric traits (BMI, WHR) we performed lookups from the summary statistics of the GIANT

188 consortium. For lipid traits (i.e. TG, HDL, CHOL), we looked up association results from the Global Lipid

189 Consortium. 30

190 RESULTS

191 Table S-3 shows the characteristics of the three psychiatric samples. The discovery sample included

192 patients with the shortest treatment duration (median of 6 months versus 27.4 and 36 months in the

193 replication 1 and 2, respectively, $\mathrm{p}=0.0001$ ), as well as the lowest BMl (current median BMI of 25 versus 
19428 and $27 \mathrm{~kg} / \mathrm{m}^{2}$ for replication 1 and 2, respectively, $\mathrm{p}=0.0001$ ) and the lowest prevalence of obesity

$195\left(\mathrm{BMl} \geq 30 \mathrm{~kg} / \mathrm{m}^{2}\right)(18 \%$ versus $40 \%$ and $27 \%$, respectively, $\mathrm{p}<0.001)$.

196 Association of $P C K 1$ polymorphisms with BMI in psychiatric populations

197 Table S-2 shows PCK1 genotype distribution among the three psychiatric samples. No significant 198 associations were found between PCK1 polymorphisms and baseline BMI when exploratory analyses

199 were conducted (Table S-4). However, a trend and a significant association was found between

200 rs11552145 and rs2071023 and current BMl (BMI at the last follow-up assessment) in the discovery (p-

201 corrected 0.08 and 0.018 , respectively) and in the combined sample ( $p$-corrected 0.01 and 0.003 ,

202 respectively). Figure 1 shows the association of PCK1 rs11552145 polymorphism with BMI.

203 Multivariate analyses were first conducted in the discovery sample for the four SNPs (Table 1). Carriers of

204 rs 11552145- $A A$ genotype had, on average, 2.20 lower BMI units when compared to carriers of G-allele

$205(p=0.0004)$. Similar results were found for $r s 2071023-C C$ genotype which had 1.27 lower BMI units when

206 compared to $G$-allele carriers $(p=0.004)$. Significant results were replicated for $r s 11552145$ and BMI

207 when combining the 2 replication samples. $A A$ carriers had 1.42 lower BMI units when compared to $G$ -

208 allele carriers $(p=0.009)$. When combining the three samples similar results were found for both

$209 r s 11552145$ and $r s 2071023$ (estimates -1.89 and $-1.11 \mathrm{~kg} / \mathrm{m}^{2}$ and $p<0.001$ and $p<0.001$, respectively).

210 Explained variances in the combined sample for $r s 11552145$ and $r s 2071023$ were $0.65 \%$ and $0.85 \%$,

211 respectively. For both rs11552145 and rs2071023, further analyses stratified by sex and age were 
212 conducted in the three samples combined. rs2071023 was associated with BMI only in women whereas

213 for rs 11552145 an association was found in both genders, but a stronger association was found among

214 women younger than 45 years, where rs 11552145 AA-carriers had 2.25 lower BMI units when compared

215 to G-allele carriers ( $p$-value 0.009 , explained variance $0.77 \%$ ). No significant results were found for the

216 other two SNPs rs8123020 and rs707555.

$217 P C K 1$ polymorphisms and metabolic parameters in psychiatric populations

218 The association of rs11552145 and rs2071023 with other metabolic parameters (i.e. WC, BGL, CHOL,

$219 \mathrm{HDL}, \mathrm{LDL}$ and TG) was analyzed in the discovery sample (Table 2). In agreement with results on BMI,

220 both carriers of $r s 11552145-A A$ genotype and $r s 2071023-C C$ genotype had significantly lower WC (-6.86

221 and $-3.45 \mathrm{~cm}, \mathrm{p}$-values 0.008 and 0.004 , respectively). In addition, $r s 11552145-A A$ genotype carriers had

222 lower TG levels when compared to $G$-allele carriers $(-27.59 \mathrm{mg} / 100 \mathrm{~mL}$, p-value $<0.002)$.

223 Association of CRTC1 and PCK1 with BMI

224 Since PCK1 is a downstream gene of CRTC1, we wanted to further analyze the association of both

225 CRTC1 rs3746266A>G previously associated with BMI11 and $P C K 1$ rs11552145G>A with BMl over

226 treatment duration (Figure 2). In the combined analysis, CRTC1 G-allele and PCK1 AA genotype were

227 pooled together since carriers of these alleles showed lower BMI units when compared to others when

228 analyzed individually. Thus, in the multivariate analysis adjusted by age, sex, treatment and treatment 
229 duration ( $\mathrm{n}=610$ ), those carriers of $A A$ genotype for $C R T C 1$ and $P C K 1$ or carriers of G-allele of CRTC1

230 and $P C K 1$ had 0.79 less units of BMI when compared to the reference group ( $p$ 0.009). Similarly, carriers

231 of PCK1 AA genotype and CRTC1 G-allele had 2.43 less units of BMI compared to the reference group

$232(p<0.001)$.

\section{Functional relevance of $P C K 1$ polymorphisms}

234 We explored further the functional relevance of $P C K 1$ polymorphisms. For $r s 11552145$ and $r s 707555$, the

235 two variants in coding regions, PolyPhen- $2^{34}$ predicted both mutations to be benign. Further analysis on

236 gene expression platform (GTEX portal ${ }^{35}$ ) showed significant differences in rs11552145 expression in

237 subcutaneous adipose tissue with homozygous carriers of the variant allele having lower expression ( $p$

238 0.03). No differences were found for rs707555, rs8123020 or rs2071023.

$239 \quad P C K 1$ polymorphisms in population-based samples

240 The association of $r s 6070157$ (proxy of $r s 11552145, r^{2}=0.97$ ) and $r s 2071023$ with BMI and other

241 metabolic features was further analyzed for replication in three population-based samples (GIANT,

242 CoLaus and Global Lipids Genetics Consortium). Significant associations were found between the two

243 PCK1 polymorphisms and the WHR in the GIANT cohort $\left(\mathrm{N}=1233^{\prime} 865\right)$ for women and for both genders

244 combined. In addition, significant associations were found for rs2071023 with HDL and TGL in the Global

245 Lipids Genetics Consortium (N=100'184; p-values: 0.003 and 0.03, respectively) (Table 3). 


\section{DISCUSSION}

247 Growing evidence supports that $P C K$ can contribute to obesity and metabolic syndrome both in animal

248 models and in the general population. ${ }^{12-14,16,17}$ The main results from this study suggest that carriers of

249 PCK1 rs11552145-AA genotype have lower BMI when compared to G-allele carriers in psychiatric

250 patients treated with weight gain inducing drugs, this association being found in the discovery sample and

251 in the replication samples analyzed together. Moreover, low WC and TG levels were associated with

252 rs 11552145-AA in the discovery sample and low BMI and WC were found as well for rs2071023-CC

253 genotype. To our knowledge, this is the first study carried out in psychiatric patients and the first one to

254 find a positive association between PCK1 polymorphisms and BMI.

255 In addition, as a proof of concept, a positive association was found in the general population (GIANT

256 cohort) with WHR and $r s 6070157$ (proxy of $r s 11552145, r^{2}=0.99$ ) and $r s 2071023$, again suggesting an

257 association of the polymorphisms with obesity traits, although the value was much weaker than in

258 psychiatric samples and being of no clinical significance in the general population. This goes in the same

259 line of what we found in previous results, ${ }^{11}$ since psychiatric populations are at high risk of obesity and/or

260 metabolic syndrome. PCK1 function has been previously associated in animal models with glucose and

261 lipid homeostasis and also with weight gain. ${ }^{36}$ In humans, the main investigated polymorphism is the -

262 232C/G (rs2071023) which is located in the promoter region of PCK1. This polymorphism has been

263 previously associated with type 2 diabetes (T2DM) and gestational diabetes mellitus (GDM) but with 
264 conflicting results in different ethnicities. Positive associations were found among South Asian and 265 Japanese populations ${ }^{20,37}$ concluding that carriers of the minor allele $(G G)$ were at risk of developing 266 T2DM, whereas no significant findings were found in German or Danish Caucasian populations. ${ }^{18,} 21$

267 Finally, a case series study conducted in 3 Maltese women found that those who developed GDM carried

268 the homozygous variant allele, but these results must be replicated in larger cohorts. ${ }^{38}$ In the present

269 study, no association was found between rs2071023 and BGL, although the diabetes phenotype was not

270 assessed. Additionally, and consistent with our results, another PCK1 polymorphism (rs707555) showed

271 no significant association with anthropometric traits such as WC, weight and fat mass or BMI.22, 39

272 Analyses were conducted in the combined discovery and replication samples for treatment duration up to

27324 months. Different effect sizes, detected in the discovery versus the replication samples, could be

274 explained by lower prevalence of obesity at baseline and shorter treatment durations in the discovery

275 sample (Table S-3), since both baseline BMI and treatment duration are moderators of weight gain. 40

276 However, to exclude a winner's curse event, these results need to be replicated in other short treatment

277 duration samples.

278 Of note, in the present study as in previous genetic studies, genetically explained variances of BMI are

279 quite low suggesting that BMI and metabolic features are influenced by multiple genetic factors as

280 previously described in the literature. ${ }^{4}$ However, in the present study, rs11552145 was strongly

281 associated with BMI in the subgroup of women younger than 45 years and the observed difference in BMI 
282 between genotypes is of clinical significance. This result is in agreement with our previous study showing 283 that the association between a polymorphism of CRTC1 (an upstream gene of PCK 1) and BMI was

284 higher in women younger than 45 years as compared to non-gender stratified sample. ${ }^{11}$ In addition, a

285 positive correlation was found between PCK1 mRNA expression levels and BMI in a study conducted

286 with non-menopausal women. ${ }^{15}$ Other pharmacogenetic studies also highlighted the importance of

287 stratifying by sex. 41,42 This finding could be tentatively explained by the influence of estrogen circulating

288 levels on energy balance. ${ }^{43}$ Thus, a lack of estrogen in mice was related to obesity, decreasing fasting

289 blood glucose levels, activating AMPK and reducing the expression of gluconeogenic genes, such as

290 PCK in the liver. ${ }^{44,} 45$ However, this hypothesis could not be tested in our samples as estrogen circulating

291 levels were not measured.

292 In order to assess the contribution of PCK1 and CRTC1 polymorphisms on BMI, analyses combining both

293 SNPs were conducted. An additive association with BMI was observed over treatment duration among

294 carriers of CRTC1 rs3746266 G-allele and PCK1 rs11552145 AA genotype which had lower BMI when

295 compared to the reference group. As described elsewhere, ${ }^{46}$ PCK family genes contain in their promoter

296 region a CREB-regulated element binding site where CRTC1 binds, enhancing PCK expression. In the

297 present study, the strongest associations were found among psychiatric population under psychotropic

298 treatment which could be explained by the additive effect between PCK1 and CRTC1 genes and

psychotropic drugs. In particular, CRTC1 is modulated, among other mechanisms, by adenosine 
monophosphate protein kinase (AMPK) which is increased by antipsychotics. ${ }^{47}$ Besides, several

301 polymorphisms on the $A M P K$ gene, showed an association with weight gain induced by antipsychotics. ${ }^{48}$

302 AMPK has also been related to gluconeogenesis modulation. ${ }^{49}$ Another study conducted in rats showed

303 that olanzapine increased the mRNA levels of glucose-6-phosphatase in the liver. ${ }^{47}$ Although little is

304 known about PCK family genes and psychotropic drugs, PCK expression is inhibited by lithium in isolated

305 hepatocytes from fasted rats ${ }^{50}$. In addition, chronic clozapine administration upregulates $P C K$ expression

306 in rat liver. ${ }^{51}$ Therefore, several genes coding for enzymes implicated in the gluconeogenic pathway have

307 been associated with antipsychotics.

308 Finally, in our sample, higher associations were found among psychiatric patients rather than in general

309 population possibly explained by the high prevalence of overweight or obesity in psychiatric patients

310 induced by the illness, the lifestyle (diet, physical activity), in addition to the direct effect of drug inducing

311 weight gain.

312 Some limitations of the present study must be mentioned. Firstly, patients were not drug naive, therefore,

313 we could not assess whether the association between the polymorphisms and BMI or other phenotypes

314 was influenced by the psychiatric illness itself and/or by the psychotropic treatment. Secondly, although

315 the main inclusion criteria for patients in the present study was that they were receiving psychotropic

316 drugs known to induce weight gain (i.e aripiprazole, amisulpride, clozapine, olanzapine, quetiapine,

317 risperidone, mirtazapine, lithium and/or valproate), other drugs possibly inducing weight (psychotropic 
318 and/or somatic drugs) were prescribed, the influence of which could not be evaluated. This study was

319 conducted in Caucasians, thus results cannot be extrapolated to other ethnicities. Not all tagging SNPs

320 could be tested due to limited availability of the genotypes. In addition, no significant associations with

321 BMI were found for the two other tested SNPs (rs707555 and rs8123020), either because of a lack of

322 effect or a lack of power due to the low MAF. Further replications of this study should increase sample

323 size in order to test low MAF polymorphisms and to increase the coverage of $P C K 1$ gene by including

324 other tagging SNPs. Finally, variants obtained through GWAS should be also considered in further

325 analysis, in particular those on gluconeogenic pathway. It has thus been recently shown that PCK1

326 expression is regulated by $C A M K 1 D, 52$ a gene previously related to diabetes in GWAS. ${ }^{53}$

327 In conclusion, this is the first study investigating the association of $P C K 1$ polymorphisms with BMI and

328 other metabolic traits in psychiatric populations. Higher associations were found in psychiatric patients

329 treated with psychotropic drugs over short periods, and in women younger than 45 years. In addition, the

330 present study supports research on pathway related genes such as CRTC1 and PCK1, which may have

331 an additive association with BMI. Further studies on the same and other pathways are therefore

332 warranted, to increase our knowledge on the multiple genetic risk factors influencing obesity, lipid

333 disturbances or metabolic syndrome in psychiatric population. This could ultimately help, by the

334 determination and the combination of multiple genetic and clinical risk factors, to better adapt

335 pharmacological treatments among particular populations at risk. 
337 The authors thank Dr. S. Crettol, C. Brogli, V. Hodel (logistical assistance), E. Retamales (bibliographical

338 help), A. C. Aubert, M. Brocard, N. Cochard, M. Delessert, A. Kottelat, M. Brawand, K. Powell Golay, S.

339 Jaquet (sample analysis). We thank the GIANT consortium for access to their BMI association result in

340 123'807 individuals and Global Lipids Genetics Consortium.

341

342

343 
344

345

346

347

348

349

350

351

352

353

354

355

356

357

358

359

360

361

362

363

364

365

366

\section{REFERENCES}

1. Nihalani N, Schwartz TL, Siddiqui UA et al. Obesity and psychotropic. CNS Neuroscience and Therapeutics. 2012; 18:57-63.

2. De Hert M, Dekker JM, Wood D et al. Cardiovascular disease and diabetes in people with severe mental illness position statement from the European Psychiatric Association (EPA), supported by the European Association for the Study of Diabetes (EASD) and the European Society of Cardiology (ESC). Eur Psychiatry. 2009; 24:412-424.

3. Laursen TM, Munk-Olsen T, Vestergaard M. Life expectancy and cardiovascular mortality in persons with schizophrenia. Curr Opin Psychiatry. 2012; 25:83-88.

4. Speliotes EK, Willer CJ, Berndt SI et al. Association analyses of 249,796 individuals reveal 18 new loci associated with body mass index. Nat Genet. 2010; 42:937-948.

5. Balt SL, Galloway GP, Baggott MJ et al. Mechanisms and genetics of antipsychotic-associated weight gain. Clin Pharmacol Ther. 2011; 90:179-183.

6. Kao AC, Muller DJ. Genetics of antipsychotic-induced weight gain: update and current perspectives. Pharmacogenomics. 2013; 14:2067-2083.

7. Beale EG, Harvey BJ, Forest C. PCK1 and PCK2 as candidate diabetes and obesity genes. Cell Biochem Biophys. 2007; 48:89-95.

8. Yang J, Kalhan SC, Hanson RW. What is the metabolic role of phosphoenolpyruvate carboxykinase? J Biol Chem. 2009; 284:27025-27029.

9. Kotelevtsev Y, Holmes MC, Burchell A et al. 11beta-hydroxysteroid dehydrogenase type 1 knockout mice show attenuated glucocorticoid-inducible responses and resist hyperglycemia on obesity or stress. Proc Natl Acad Sci U S A. 1997; 94:14924-14929. 
367

368

369

370

3711019.

372

373

$374 \quad 55: 273-280$.

375 13. Valera A, Pujol A, Pelegrin M et al. Transgenic mice overexpressing phosphoenolpyruvate

376

377

378

379

10. Oh KJ, Han HS, Kim MJ et al. CREB and FoxO1: two transcription factors for the regulation of hepatic gluconeogenesis. BMB Rep. 2013; 46:567-574.

11. Choong E, Quteineh L, Cardinaux JR et al. Influence of CRTC1 polymorphisms on body mass index and fat mass in psychiatric patients and in the general adult population. Jama Psychiatry 2013; 70:1011-

\section{Franckhauser S, Munoz S, Elias I et al. Adipose overexpression of phosphoenolpyruvate} carboxykinase leads to high susceptibility to diet-induced insulin resistance and obesity. Diabetes. 2006; carboxykinase develop non-insulin-dependent diabetes mellitus. Proc Natl Acad Sci U S A. 1994; 91:9151-9154.

14. Olswang $\mathrm{Y}$, Cohen $\mathrm{H}$, Papo $\mathrm{O}$ et al. A mutation in the peroxisome proliferator-activated receptor gamma-binding site in the gene for the cytosolic form of phosphoenolpyruvate carboxykinase reduces adipose tissue size and fat content in mice. Proc Natl Acad Sci U S A. 2002; 99:625-630.

15. Chang TJ, Lee WJ, Chang HM et al. Expression of subcutaneous adipose tissue phosphoenolpyruvate carboxykinase correlates with body mass index in nondiabetic women. Metabolism. 2008; 57:367-372. 16. Zhao J, Xiao P, Guo Y et al. Bivariate genome linkage analysis suggests pleiotropic effects on chromosomes 20p and 3p for body fat mass and lean mass. Genet Res (Camb). 2008; 90:259-268. 17. Lee JH, Reed DR, Li WD et al. Genome scan for human obesity and linkage to markers in $20 q 13$. Am J Hum Genet. 1999; 64:196-209.

18. Wegner L, Andersen G, Albrechtsen A et al. Large-scale study of the $-232 \mathrm{C}>\mathrm{G}$ polymorphism of PCK1 in Type 2 diabetes. Diabet Med. 2006; 23:1140-1144.

19. Dong $\mathrm{Y}$, Zhang $\mathrm{H}$, Wang $\mathrm{X}$ et al. A Leu184Val polymorphism in PCK1 gene is associated with type 2 diabetes in Eastern Chinese population with BMI<23 kg/m2. Diabetes Res Clin Pract. 2009; 83:227-232. 
391 20. Rees SD, Britten AC, Bellary S et al. The promoter polymorphism -232C/G of the PCK1 gene is

392 associated with type 2 diabetes in a UK-resident South Asian population. BMC Med Genet. 2009; 10:83.

393 21. Gouni-Berthold I, Giannakidou E, Faust M et al. Association of the promoter polymorphism -232C/G

394 of the phosphoenolpyruvate carboxykinase gene (PCK1) with Type 2 diabetes mellitus. Diabet Med.

$3952006 ; 23: 419-425$.

396 22. Larsen LH, Angquist L, Vimaleswaran KS et al. Analyses of single nucleotide polymorphisms in

397 selected nutrient-sensitive genes in weight-regain prevention: the DIOGENES study. Am J Clin Nutr.

$398 \quad 2012 ; 95: 1254-1260$.

399 23. Shin HD, Park BL, Kim LH et al. Association of a polymorphism in the gene encoding

400 phosphoenolpyruvate carboxykinase 1 with high-density lipoprotein and triglyceride levels.

401 Diabetologia. 2005; 48:2025-2032.

402 24. Choong E, Solida A, Lechaire $C$ et al. Suivi du syndrome métabolique induit par les antipsychotiques

403 atypiques: recomendations et perspectives pharmacogénétiques. Rev Med Suisse. 2008; 4:1994-1999.

404 25. Hiemke C, Baumann P, Bergemann N et al. AGNP Consensus Guidelines for Therapeutic Drug

405 Monitoring in Psychiatry: Update 2011. Pharmacopsychiatry. 2011; 44:195-235.

406 26. Choong E, Bondolfi G, Etter M et al. Psychotropic drug induced weight gain and other metabolic

407 complications in a Swiss Psychiatric population. J Psychiatr Res. 2012; 46:540-548.

408 27. Firmann M, Mayor V, Vidal PM et al. The CoLaus study: a population-based study to investigate the 409 epidemiology and genetic determinants of cardiovascular risk factors and metabolic syndrome. BMC 410 Cardiovasc Disord. 2008; 8:6.

411 28. Lango Allen H, Estrada K, Lettre $\mathrm{G}$ et al. Hundreds of variants clustered in genomic loci and biological 412 pathways affect human height. Nature. 2010; 467:832-838. 
413 29. Heid IM, Jackson AU, Randall JC et al. Meta-analysis identifies 13 new loci associated with waist-hip

414 ratio and reveals sexual dimorphism in the genetic basis of fat distribution. Nat Genet. 2010; 42:949-

415960.

416 30. Teslovich TM, Musunuru K, Smith AV et al. Biological, clinical and population relevance of 95 loci for

417 blood lipids. Nature. 2010; 466:707-713.

418 31. International HapMap Consortium. The International HapMap Project. Nature. 2003; 426:789-796.

419 32. R Core Team. R: A language and environment for statistical computing, R Fondation for Statistical

420 Computing,Vienna, Austria. In: R Foundation for Statistical Computing. Vienna, Austria: R Development

421 Core Team; 2013.

422 33. Lin X, Zhang D. Inference in generalized additive mixed models by using smoothing splines. J R Statist

423 Soc B. 1999; 61:381-400.

424 34. Adzhubei IA, Schmidt S, Peshkin L et al. A method and server for predicting damaging missense 425 mutations. Nat Methods. 2010; 7:248-249.

426 35. Keen JC, Moore HM. The Genotype-Tissue Expression (GTEx) Project: Linking Clinical Data with

427 Molecular Analysis to Advance Personalized Medicine. J Pers Med. 2015; 5:22-29.

428 36. Rosella G, Zajac JD, Baker L et al. Impaired glucose tolerance and increased weight gain in transgenic 429 rats overexpressing a non-insulin-responsive phosphoenolpyruvate carboxykinase gene. Mol Endocrinol. $430 \quad 1995 ; 9: 1396-1404$.

431 37. Horikawa Y, Yamasaki T, Nakajima $\mathrm{H}$ et al. Identification of a novel variant in the

432 phosphoenolpyruvate carboxykinase gene promoter in Japanese patients with type 2 diabetes. Horm

433 Metab Res. 2003; 35:308-312.

434 38. Abou-Hussein S, Savona-Ventura C, Grima S et al. Genetic factors in risk assessment for the 435 development of type 2 diabetes mellitus in a small case series. Int J Risk Saf Med. 2011; 23:119-123. 
39. Vimaleswaran KS, Franks PW, Brage S et al. Lack of association between PCK1 polymorphisms and

437 obesity, physical activity, and fitness in European Youth Heart Study (EYHS). Obesity. 2010; 18:1975-

4381980.

439 40. De Hert M, Detraux J, van Winkel R et al. Metabolic and cardiovascular adverse effects associated

440 with antipsychotic drugs. Nat Rev Endocrinol. 2012; 8:114-126.

441 41. Vehof J, Al Hadithy AF, Burger $\mathrm{H}$ et al. Association between the ROBO1 gene and body mass index in

442 patients using antipsychotics. Psychiatr Genet. 2011; 21:202-207.

443 42. Gregoor JG, van der Weide J, Loovers HM et al. Polymorphisms of the LEP, LEPR and HTR2C gene:

444 obesity and BMI change in patients using antipsychotic medication in a naturalistic setting.

445 Pharmacogenomics. 2011; 12:919-923.

446 43. Clegg DJ, Brown LM, Woods SC et al. Gonadal hormones determine sensitivity to central leptin and 447 insulin. Diabetes. 2006; 55:978-987.

448 44. Mandour T, Kissebah AH, Wynn V. Mechanism of oestrogen and progesterone effects on lipid and 449 carbohydrate metabolism: alteration in the insulin: glucagon molar ratio and hepatic enzyme activity.

$450 \quad$ Eur J Clin Invest. 1977; 7:181-187.

451 45. Kim JY, Jo KJ, Kim OS et al. Parenteral 17beta-estradiol decreases fasting blood glucose levels in non-

452 obese mice with short-term ovariectomy. Life Sci. 2010; 87:358-366.

453 46. Hanson RW, Reshef L. Regulation of phosphoenolpyruvate carboxykinase (GTP) gene expression. 454 Annu Rev Biochem. 1997; 66:581-611.

455 47. Ikegami M, Ikeda H, Ohashi T et al. Olanzapine increases hepatic glucose production through the 456 activation of hypothalamic adenosine 5'-monophosphate-activated protein kinase. Diabetes Obes 457 Metab. 2013; 15:1128-1135. 
458 48. Souza RP, Tiwari AK, Chowdhury NI et al. Association study between variants of AMP-activated 459 protein kinase catalytic and regulatory subunit genes with antipsychotic-induced weight gain. J Psychiatr 460 Res. 2012; 46:462-468.

461 49. Kahn BB, Alquier T, Carling D et al. AMP-activated protein kinase: ancient energy gauge provides 462 clues to modern understanding of metabolism. Cell Metab. 2005; 1:15-25.

463 50. Bosch F, Rodriguez-Gil JE, Hatzoglou M et al. Lithium inhibits hepatic gluconeogenesis and 464 phosphoenolpyruvate carboxykinase gene expression. J Biol Chem. 1992; 267:2888-2893.

465 51. Tulipano G, Rizzetti C, Bianchi I et al. Clozapine-induced alteration of glucose homeostasis in the rat: 466 the contribution of hypothalamic-pituitary-adrenal axis activation. Neuroendocrinology. 2007; 85:61-70.

467 52. Haney S, Zhao J, Tiwari S et al. RNAi screening in primary human hepatocytes of genes implicated in 468 genome-wide association studies for roles in type 2 diabetes identifies roles for CAMK1D and CDKAL1, 469 among others, in hepatic glucose regulation. PLOS ONE. 2013; 8:e64946.

470 53. Zeggini E, Scott L, Saxena R et al. Meta-analysis of genome-wide association data and large-scale 471 replication identifies additional susceptibility loci for type 2 diabetes. Nat Genet. 2008; 40:638-645. 
Table 1. Multivariate analysis of PCK1 polymorphisms and BMI.

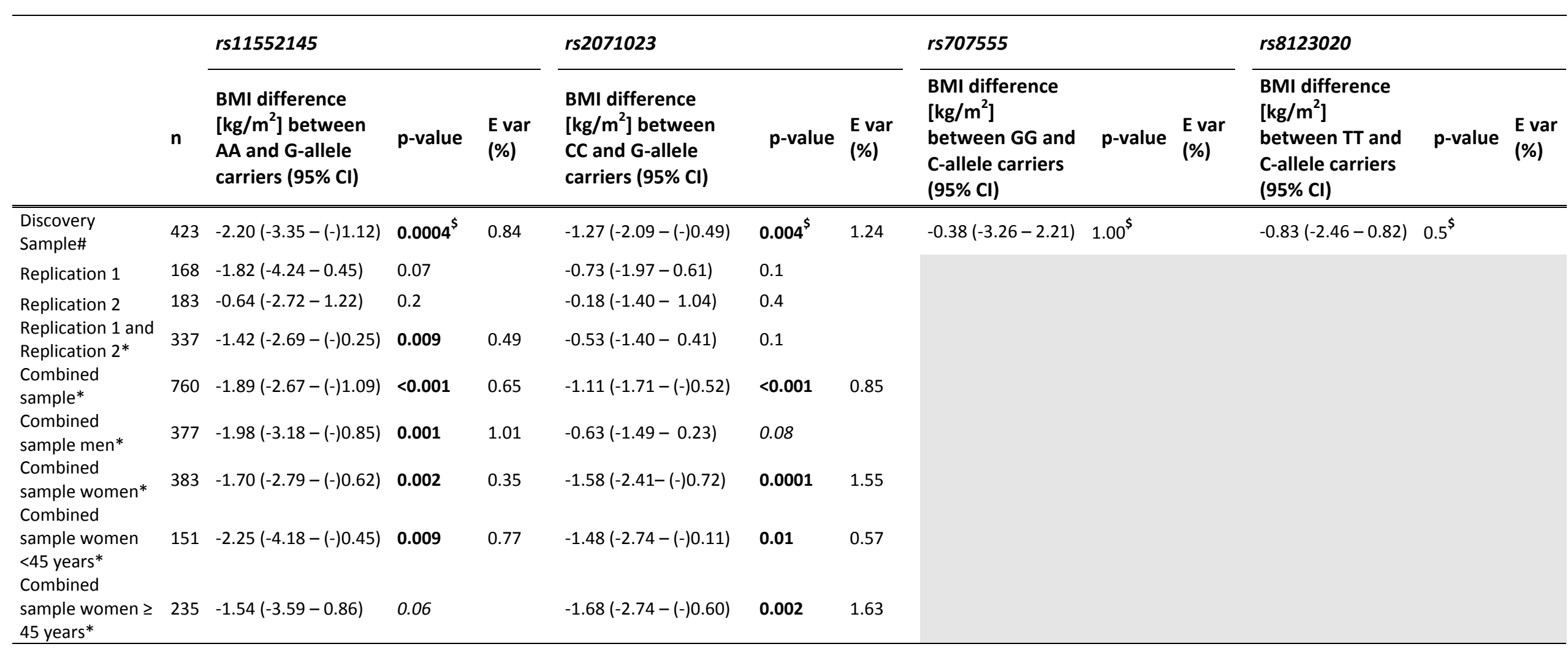

\#bootstrap at 10000 . Only significant results in discovery sample were further tested for replication.

$\$$-corrected value for discovery sample.

* Patients treated for up to 24 months.

E var (\%): explained variance by the polymorphism, only calculated for significant tests.

Adjusted by: age, sex, treatment (antipsychotic or mood stabilizer) and treatment duration. Bootstrap at 1000. 
Table 2. Association of PCK1 polymorphisms with other metabolic phenotypes in the discovery sample.

\begin{tabular}{|c|c|c|c|c|}
\hline rs11552145 & $n$ & $\begin{array}{r}\text { Difference between } \mathrm{AA} \text { and } \\
\text { G-allele carriers }(95 \% \mathrm{Cl})\end{array}$ & p-value & E.var (\%) \\
\hline$W C[\mathrm{~cm}]$ & 408 & $-6.86(-11.07-(-) 2.59)$ & 0.008 & 1.04 \\
\hline $\mathrm{HDL}^{* *}[\mathrm{mg} / 100 \mathrm{~mL}]$ & 305 & $5.85(-1.95-14.04)$ & 0.13 & \\
\hline TG** [mg / $100 \mathrm{~mL}]$ & 305 & $-27.59(-39.16-(-) 14.24)$ & $<0.002$ & 0.90 \\
\hline $\mathrm{LDL}^{* *}[\mathrm{mg} / 100 \mathrm{~mL}]$ & 299 & $-10.14(-19.89-2.34)$ & 0.12 & \\
\hline $\mathrm{CHOL}^{* *}[\mathrm{mg} / 100 \mathrm{~mL}]$ & 307 & $-10.53(-28.08-8.19)$ & 0.28 & \\
\hline $\mathrm{BGL}^{* *}[\mathrm{mg} / 100 \mathrm{~mL}]$ & 289 & $-3.6(-8.28-0.36)$ & 0.09 & \\
\hline rs2071023 & $\mathbf{n}$ & $\begin{array}{r}\text { Difference between } \mathrm{CC} \text { and } \\
\text { G-allele carriers }(95 \% \mathrm{Cl})\end{array}$ & p-value & E.var (\%) \\
\hline WC $[\mathrm{cm}]$ & 409 & $-3.45(-5.74-(-) 1.18)$ & 0.004 & 1.14 \\
\hline $\mathrm{HDL}^{* *}[\mathrm{mg} / 100 \mathrm{~mL}]$ & 305 & $1.95(-0.39-4.29)$ & 0.12 & \\
\hline TG** [mg /100 mL] & 305 & $-8.01(-19.58-3.56)$ & 0.64 & \\
\hline $\mathrm{LDL}^{* *}[\mathrm{mg} / 100 \mathrm{~mL}]$ & 299 & $-2.34(-10.14-5.07)$ & 0.54 & \\
\hline $\mathrm{CHOL}^{* *}[\mathrm{mg} / 100 \mathrm{~mL}]$ & 307 & $-3.12(-11.7-5.07)$ & 0.32 & \\
\hline $\mathrm{BGL}^{* *}[\mathrm{mg} / 100 \mathrm{~mL}]$ & 289 & $2.52(-2.16-5.94)$ & 0.42 & \\
\hline
\end{tabular}

**Fasting patients

$\$$ p-corrected value for discovery sample.

E. var (\%): explained variance by the polymorphism (\%) calculated only for significant tests.

Adjusted by: BMI, age, sex, treatment (antipsychotic or mood stabilizer) and treatment duration. Bootstrap at 1000. WC: waist circumference, HDL: high lipoprotein, TG: triglycerides, CHOL: cholesterol, BGL: blood glucose levels 
Table 3. Association of $P C K 1$ polymorphisms with metabolic traits in population based samples.

\begin{tabular}{|c|c|c|c|c|c|c|}
\hline \multirow[b]{2}{*}{$\begin{array}{l}r s 6070157 \\
\text { (proxy of } r s 11552145, r^{2}=0.99 \text { ) }\end{array}$} & \multicolumn{2}{|l|}{$\begin{array}{l}\text { CoLaus } \\
\left(n=5^{\prime} 338\right)\end{array}$} & \multicolumn{2}{|l|}{$\begin{array}{l}\text { GIANT } \\
\left(n=123^{\prime} 865\right)\end{array}$} & \multicolumn{2}{|c|}{$\begin{array}{l}\text { Global Lipids Genetics } \\
\text { Consortium }\left(n=100^{\prime} 184\right)\end{array}$} \\
\hline & $\beta(\mathrm{SE})$ & $\mathrm{p}$-value & $\beta(\mathrm{SE})$ & $p$-value & $\boldsymbol{\beta}(\mathrm{SE})$ & $\mathrm{p}$-value \\
\hline \multicolumn{7}{|l|}{ Anthropometric traits } \\
\hline BMI [kg/m2] & $-0.0016(0.0258)$ & 0.95 & $0.0025(0.0053)$ & 0.63 & N.A & N.A \\
\hline WC $[\mathrm{cm}]$ & $-0.0026(0.0258)$ & 0.92 & N.A & N.A & N.A & N.A \\
\hline WHR & $-0.0123(0.0258)$ & 0.63 & $-0.0163(0.0071)$ & 0.02 & N.A & N.A \\
\hline Men & $0.0086(0.038)$ & 0.82 & $0.0151(0.0096)$ & 0.11 & N.A & N.A \\
\hline Women & $-0.0308(0.035)$ & 0.39 & $-0.0202(0.0089)$ & 0.02 & N.A & N.A \\
\hline \multicolumn{7}{|l|}{ Lipids } \\
\hline $\mathrm{HDL}$ [mg /100 mL] & $0.38(0.37)$ & 0.30 & N.A & N.A & $0.16(0.12)$ & 0.20 \\
\hline $\mathrm{CHOL}[\mathrm{mg} / 100 \mathrm{~mL}]$ & $-0.14(1.02)$ & 0.89 & N.A & N.A & $0.05(0.12)$ & 0.69 \\
\hline TG [mg /100 mL] & $-3.25(2.57)$ & 0.21 & N.A & N.A & $-0.10(-0.28)$ & 0.73 \\
\hline LDL [mg /100 mL] & $-0.41(0.90)$ & 0.65 & N.A & N.A & N.A & N.A \\
\hline BGL [mg / $100 \mathrm{~mL}]$ & $0.85(0.55)$ & 0.12 & N.A & N.A & $-0.06(-0.08)$ & 0.50 \\
\hline$r s 2071023$ & $\boldsymbol{\beta}(\mathrm{SE})$ & $\mathrm{p}$-value & $\beta(S E)$ & $p$-value & $\beta(\mathrm{SE})$ & $\mathrm{p}$-value \\
\hline \multicolumn{7}{|l|}{ Anthropometric traits } \\
\hline BMI [kg/m2] & $-0.0196(0.0198)$ & 0.32 & $-0.0028(0.0043)$ & 0.2 & N.A & N.A \\
\hline $\mathrm{WC}[\mathrm{cm}]$ & $-0.0087(0.0198)$ & 0.66 & N.A & N.A & N.A & N.A \\
\hline WHR & $0.0026(0.0198)$ & 0.90 & $-0.0195(0.0057)$ & 0.001 & N.A & N.A \\
\hline Men & $-0.0145(0.029)$ & 0.61 & $-0.0013(0.0077)$ & 0.87 & N.A & N.A \\
\hline Women & $0.0184(0.028)$ & 0.50 & $-0.0154(0.0071)$ & 0.03 & N.A & N.A \\
\hline \multicolumn{7}{|l|}{ Lipids } \\
\hline $\mathrm{HDL}$ [mg /100 mL] & $-0.54(0.28)$ & 0.06 & N.A & N.A & $0.28(0.12)$ & 0.003 \\
\hline $\mathrm{CHOL}[\mathrm{mg} / 100 \mathrm{~mL}]$ & $-0.99(0.78)$ & 0.20 & N.A & N.A & $0.078(0.12)$ & 0.54 \\
\hline TG [mg /100 mL] & $1.11(1.98)$ & 0.57 & N.A & N.A & $-0.61(-0.28)$ & 0.03 \\
\hline LDL [mg /100 mL] & $-0.58(0.69)$ & 0.41 & N.A & N.A & N.A & N.A \\
\hline BGL [mg /100 mL] & $-0.35(0.42)$ & 0.41 & N.A & N.A & $-0.09(-0.07)$ & 0.16 \\
\hline
\end{tabular}

N.A: Data not available. BMI: Body Mass Index, WC: waist circumference, WHR: waist-to-hip ratio, HDL: high lipoprotein cholesterol, CHOL: cholesterol, TG: triglycerides, LDL: low lipoprotein cholesterol, BGL: blood glucose levels. 
Figure 1. BMI in relation to $r s 11552145$ G>A genotypes in the combined sample presented at different time periods of the current psychotropic treatment.

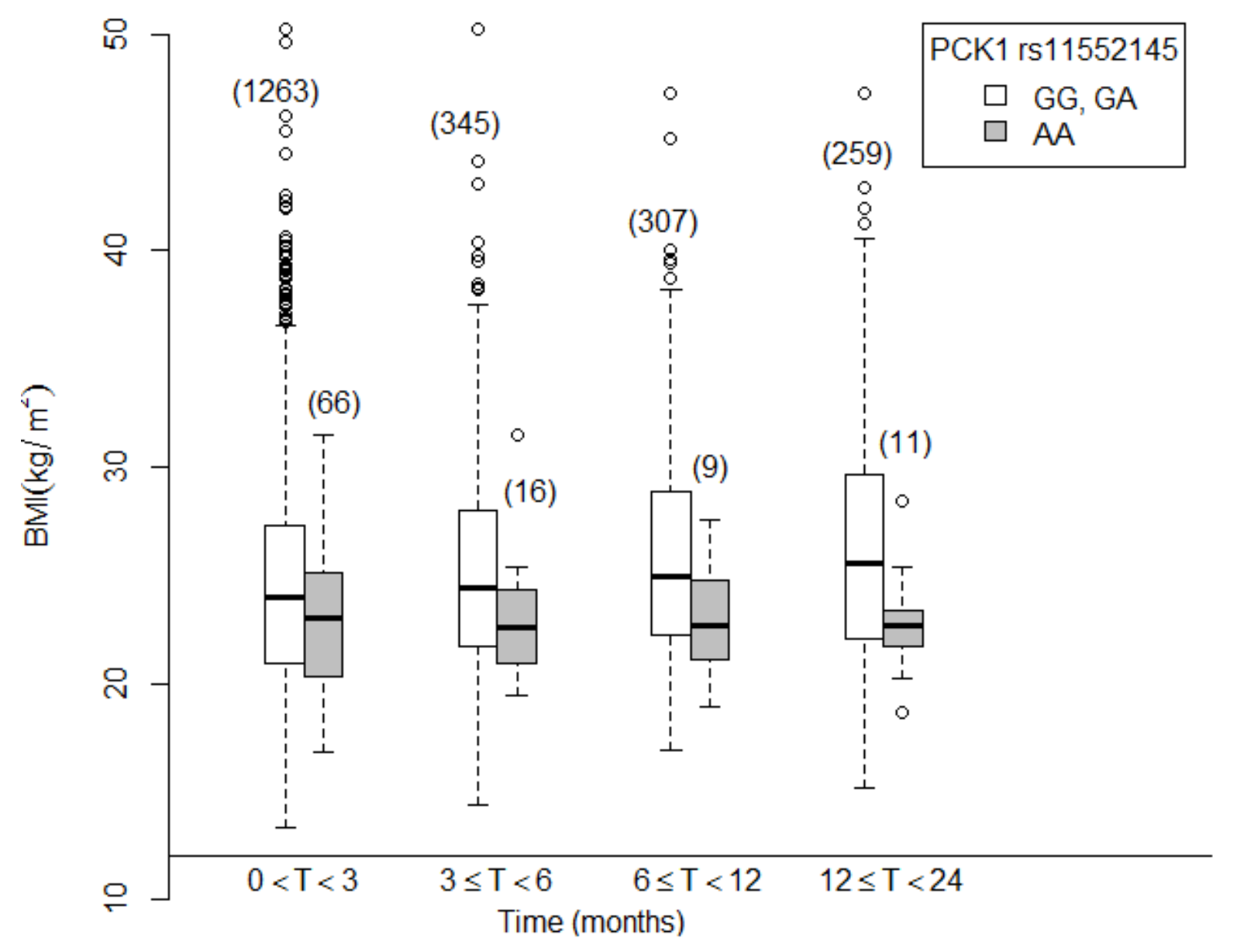

Boxplots show median values of BMI for each time of the treatment duration (solid horizontal line), $25^{\text {th }}$ and $75^{\text {th }}$ percentile values (box outline), the lowest and upper value within 1.5 Interquartile range (whiskers) and outlier values (open circles). 
Figure 2. Association of PCK1 rs11552145 and CRTC1 rs3746266 genotypes with BMI over the time in all samples.

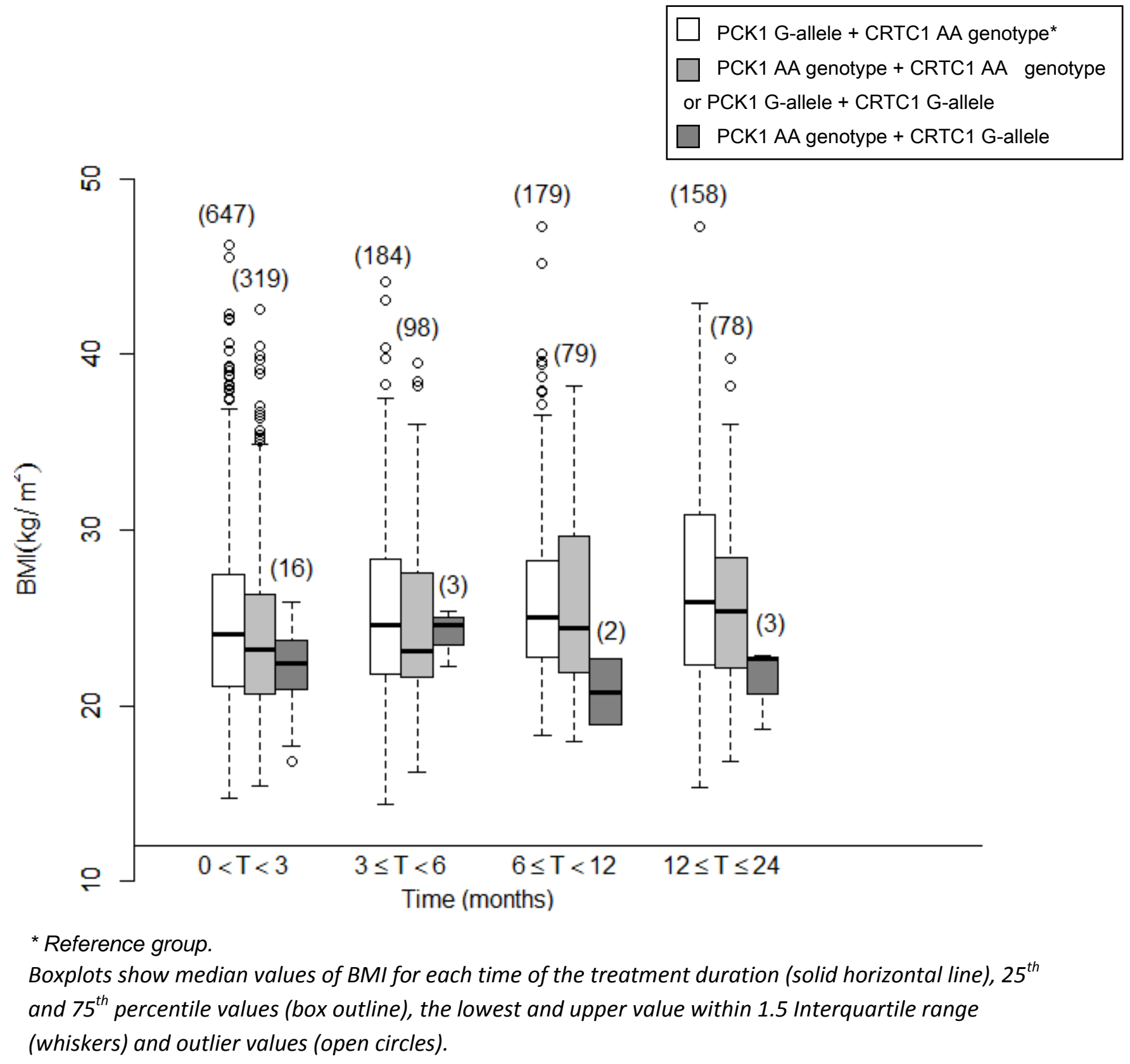


Table S-1. Selected descriptions of polymorphisms and Minor Allele Frequencies (MAF).

\begin{tabular}{llllrr}
\hline variant & \multirow{2}{*}{ position in gene } & \multirow{2}{*}{ type of variation } & $\begin{array}{l}\text { major / } \\
\text { minor allele }\end{array}$ & $\begin{array}{l}\text { MAF in combined } \\
\text { psychiatric sample }\end{array}$ & $\begin{array}{l}\text { MAF in } \\
\text { Caucasians* }\end{array}$ \\
\hline \hline rs11552145 & chr 20:56138648 & missense Glu>Lys & G/A & 0.17 & 0.16 \\
rs707555 & chr 20:56137895 & missense Leu>Val & G/C & 0.12 & 0.14 \\
rs8123020 & chr 20:56137061 & intron variant & C/T & 0.12 & 0.12 \\
rs2071023 & chr 20:56135934 & 5' near gene & C/G & 0.46 & 0.48 \\
\hline *Source: 1000 Genomes project (http://www.ensembl.org/index.html) & & &
\end{tabular}


Table S-2. HWE and PCK1 genotypes distribution among three psychiatric cohorts.

\begin{tabular}{|c|c|c|c|c|}
\hline rs11552145 & Discovery sample & Replication 1 & Replication 2 & Combined Sample \\
\hline GG & 478 & 141 & 173 & 792 \\
\hline GA & 197 & 49 & 72 & 318 \\
\hline AA & 30 & 8 & 11 & 49 \\
\hline HWE ( $p^{\$}$-value) & 0.40 & 0.68 & 1.00 & 0.08 \\
\hline rs707555 & Discovery sample & Replication 1 & Replication 2 & Combined Sample \\
\hline CC & 547 & 166 & 190 & 903 \\
\hline CG & 142 & 29 & 61 & 232 \\
\hline GG & 16 & 3 & 6 & 25 \\
\hline HWE ( $p^{\$}$-value) & 0.28 & 0.80 & 1.00 & 0.12 \\
\hline$r s 8123020$ & Discovery sample & Replication 1 & Replication 2 & Combined Sample \\
\hline CC & 546 & 140 & 193 & 879 \\
\hline CT & 149 & 55 & 62 & 266 \\
\hline $\mathrm{TT}$ & 11 & 3 & 2 & 16 \\
\hline HWE ( $p^{\$}$-value) & 1.00 & 1.00 & 0.84 & 1.00 \\
\hline rs2071023 & Discovery sample & Replication 1 & Replication 2 & Combined Sample \\
\hline CC & 217 & 52 & 69 & 338 \\
\hline CG & 333 & 103 & 122 & 558 \\
\hline GG & 153 & 41 & 53 & 247 \\
\hline HWE ( $p^{\$}$-value) & 0.96 & 1.00 & 1.00 & 1.00 \\
\hline
\end{tabular}


Table S-3. Description of demographic and clinical psychiatric Caucasian samples.

\begin{tabular}{|c|c|c|c|c|}
\hline Characteristics & $\begin{array}{l}\text { Discovery } \\
\text { Sample } \\
n=478\end{array}$ & $\begin{array}{l}\text { Replication } \\
\text { Sample } 1 \\
n=168\end{array}$ & $\begin{array}{l}\text { Replication } \\
\text { Sample } 2 \\
\mathbf{n = 1 8 8}\end{array}$ & $\begin{array}{l}\text { Combined } \\
\text { sample } \\
n=834\end{array}$ \\
\hline Male,\% & 44 & 53 & 62 & 50 \\
\hline Age, median (range), years & $50(12-96)$ & $42(19-64)$ & $42(19-69)$ & $45(12-96)$ \\
\hline \multicolumn{5}{|l|}{ Diagnosis } \\
\hline Psychotic disorders, $\%$ & 33.3 & 27.5 & 43.4 & 34.5 \\
\hline Schizo-affective disorders, $\%$ & 6.5 & 15.6 & 12.1 & 10 \\
\hline Bipolar disorders, $\%$ & 19.9 & 32.9 & 17 & 22.2 \\
\hline Depression disorders, $\%$ & 20.4 & 16.8 & 13.7 & 17.9 \\
\hline Others diagnosis,\% & 19.9 & 7.2 & 13.7 & 15.4 \\
\hline \multicolumn{5}{|l|}{ Initial BMI status ${ }^{\ddagger}$} \\
\hline BMI, median (range), $\mathrm{kg} / \mathrm{m}^{2}$ & $24(13-44)$ & $25(15-46)$ & $25(16-46)$ & $24(13-46)$ \\
\hline Overweight ( $25 \geq$ Initial BMI<30), \% & 23 & 36 & 32 & 28 \\
\hline Obese (Initial BMI $\geq 30$ ), \% & 14 & 15 & 15 & 14 \\
\hline \multicolumn{5}{|l|}{ Current BMI status $\#$} \\
\hline BMI, median (range), $\mathrm{kg} / \mathrm{m}^{2}$ & $25(15-50)$ & $28(16-42)$ & $27(17-44)$ & $25(15-50)$ \\
\hline Overweight ( $25 \geq$ Current BMI<30), \% & 26 & 30 & 34 & 27 \\
\hline Obese (Current BMI $\geq 30$ ), \% & 18 & 40 & 27 & 24 \\
\hline \multicolumn{5}{|l|}{ Initial waist circumference ${ }^{\ddagger}$} \\
\hline WC, median (range), cm & $90(54-138)$ & -- & -- & $87(54-138)$ \\
\hline High WC $\geq 94 \mathrm{~cm}$ (male), $88 \mathrm{~cm}$ (female), $\%$ & $43(n=315)$ & -- & -- & $43(n=315)$ \\
\hline \multicolumn{5}{|l|}{ Current waist circumference ${ }^{\#}$} \\
\hline WC, median (range), cm & $93(48-162)$ & -- & $98(51-148)$ & $95(48-162)$ \\
\hline High WC $\geq 94$ (male), 88 (female), \% & $54(n=592)$ & -- & $64(n=182)$ & $57(n=774)$ \\
\hline \multicolumn{5}{|l|}{ Initial Lipid status ${ }^{\ddagger}$} \\
\hline High LDL, \% (n) ${ }^{a}$ & $9(n=224)$ & -- & -- & $9(n=224)$ \\
\hline High TG, \% (n) & $19(n=234)$ & -- & -- & $19(n=234)$ \\
\hline Low HDL, \% (n) ${ }^{c}$ & $25(n=222)$ & -- & -- & $25(n=222)$ \\
\hline \multicolumn{5}{|l|}{ Current Lipid status $\#$} \\
\hline High LDL, \% (n) ${ }^{a}$ & $14(n=383)$ & -- & -- & $15(n=363)$ \\
\hline High TG, \% (n) & $28(n=402)$ & -- & -- & $28(n=402)$ \\
\hline Low HDL, \% (n) ${ }^{c}$ & $27(n=359)$ & $28(n=164)$ & $19(n=160)$ & $26(n=665)$ \\
\hline Smoker, \% & 41 & 60 & 75 & 50 \\
\hline
\end{tabular}




\begin{tabular}{lllll}
\hline & $\begin{array}{l}\text { Discovery } \\
\text { Sample } \\
\mathbf{n = 4 7 8}\end{array}$ & $\begin{array}{l}\text { Replication } \\
\text { Sample 1 } \\
\mathbf{n = 1 6 8}\end{array}$ & $\begin{array}{l}\text { Replication } \\
\text { Sample 2 } \\
\mathbf{n = 1 8 8}\end{array}$ & $\begin{array}{l}\text { Combined } \\
\text { sample } \\
\mathbf{n = 8 3 4}\end{array}$ \\
\hline \hline $\begin{array}{l}\text { Prescribed psychotropic drug } \\
\text { Amisulpride, \% }\end{array}$ & 8 & - & 10 & 7 \\
Aripirazole, \% & 10 & - & 8 & 8 \\
Clozapine, \% & 8 & 14 & 9 & 9 \\
Olanzapine, \% & 10 & 16 & 12 & 11 \\
Quetiapine, \% & 31 & 18 & 23 & 28 \\
Risperidone, \% & 16 & 17 & 16 & 16 \\
Lithium, \% & 7 & 20 & 12 & 10 \\
$\quad$ Valproate, \% & 4 & 14 & 8 & 6 \\
$\begin{array}{l}\text { Treatment duration, median (range), } \\
\text { months }\end{array}$ & $6(1-12)$ & $27.4(3-333)$ & 36 (1-390) & 9 (1-390) \\
\hline
\end{tabular}

\# Before the current psychotropic treatment

\# For replication Sample 1, 2 : current observation ; for discovery cohort : last follow-up

-- Missing clinical values or obtained in non fasting conditions

a. High LDL cholesterol : equal or higher than $160 \mathrm{mg} / 100 \mathrm{~mL}$

b. High triglycerides : equal or higher than $196 \mathrm{mg} / 100 \mathrm{~mL}$

c. Low HDL cholesterol : lower than $39 \mathrm{mg} / 100 \mathrm{~mL}$

BMI: body mass index, WC: waist circumference, LDL: low density lipoprotein, TG: triglycerides, HDL:

high density lipoprotein 
Table S-4. Exploratory analysis of the association of PCK1 polymorphisms with BMI in the three psychiatric samples.

\begin{tabular}{|c|c|c|c|c|c|c|c|c|c|c|c|c|c|}
\hline \multirow{13}{*}{ 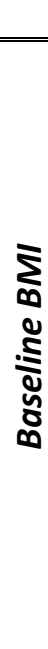 } & \multirow[b]{2}{*}{ rs11552145 } & \multicolumn{3}{|c|}{ Discovery Sample $^{\#}$} & \multicolumn{3}{|c|}{ Replication 1} & \multicolumn{3}{|c|}{ Replication 2} & \multicolumn{3}{|c|}{ Combined Sample* } \\
\hline & & AA & G-allele & p-value $\$$ & AA & G-allele & p-value & AA & G-allele & p-value & AA & G-allele & p-value \\
\hline & $n$ & 22 & 354 & \multirow[b]{2}{*}{0.36} & 8 & 131 & \multirow[b]{2}{*}{0.49} & 10 & 169 & \multirow[b]{2}{*}{0.46} & 40 & 654 & \multirow[b]{2}{*}{0.05} \\
\hline & $\mathrm{BMI}\left[\mathrm{kg} / \mathrm{m}^{2}\right]$ (SE) & $22.4(0.7)$ & $24.3(0.3)$ & & $24.3(1.4)$ & $25.5(0.4)$ & & $23.8(0.7)$ & $25(0.4)$ & & $23.1(0.5)$ & $24.7(0.2)$ & \\
\hline & $r s 707555$ & GG & C-allele & p-value ${ }^{\$}$ & & & & & & & & & \\
\hline & $n$ & 10 & 366 & \multirow{2}{*}{1.00} & & & & & & & & & \\
\hline & $\mathrm{BMI}\left[\mathrm{kg} / \mathrm{m}^{2}\right]$ (SE) & $23.6(6.7)$ & $24.2(5.1)$ & & & & & & & & & & \\
\hline & rs8123020 & $T T$ & C-allele & p-value ${ }^{\$}$ & & & & & & & & & \\
\hline & $n$ & 10 & 366 & \multirow{2}{*}{1.00} & & & & & & & & & \\
\hline & $\mathrm{BMI}\left[\mathrm{kg} / \mathrm{m}^{2}\right]$ (SE) & $23.4(3.1)$ & $24.2(5.2)$ & & & & & & & & & & \\
\hline & $r s 2071023$ & CC & G-allele & p-value $\$$ & CC & G-allele & p-value & CC & G-allele & p-value & CC & G-allele & p-value \\
\hline & $n$ & 122 & 277 & \multirow{2}{*}{0.28} & 33 & 106 & \multirow{2}{*}{0.66} & 46 & 130 & \multirow{2}{*}{0.58} & 194 & 496 & \multirow{2}{*}{0.048} \\
\hline & BMI $\left[\mathrm{kg} / \mathrm{m}^{2}\right]$ (SE) & $23.6(0.5)$ & $24.4(0.3)$ & & $24.8(0.6)$ & $25.6(0.5)$ & & $24.5(0.7)$ & $25.0(0.5)$ & & $24.0(0.4)$ & $24.8(0.2)$ & \\
\hline & & \multicolumn{3}{|c|}{ Discovery Sample ${ }^{\#}$} & \multicolumn{3}{|c|}{ Replication 1} & \multicolumn{3}{|c|}{ Replication 2} & \multicolumn{3}{|c|}{ Combined Sample* } \\
\hline \multirow{12}{*}{ 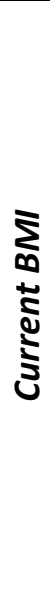 } & rs11552145 & AA & G-allele & p-value $\$$ & AA & G-allele & $p$-value & AA & G-allele & $p$-value & AA & G-allele & p-value \\
\hline & $n$ & 12 & 421 & \multirow{2}{*}{0.08} & 8 & 160 & \multirow[b]{2}{*}{0.57} & 11 & 170 & \multirow{2}{*}{0.80} & 30 & 742 & \multirow{2}{*}{0.01} \\
\hline & BMI $\left[\mathrm{kg} / \mathrm{m}^{2}\right]$ (SE) & $22.8(2.9)$ & $25.4(5.4)$ & & $27.1(1.3)$ & $28.2(0.4)$ & & $26.9(1.6)$ & $27.3(0.4)$ & & $23.3(0.6)$ & $25.7(0.2)$ & \\
\hline & rs 707555 & CC & G-allele & p-value ${ }^{\$}$ & & & & & & & & & \\
\hline & $n$ & 12 & 421 & \multirow[t]{2}{*}{1.00} & & & & & & & & & \\
\hline & $\mathrm{BMI}\left[\mathrm{kg} / \mathrm{m}^{2}\right]$ (SE) & $25.1(6.1)$ & $25.3(5.4)$ & & & & & & & & & & \\
\hline & rs8123020 & $T T$ & C-allele & p-value ${ }^{\$}$ & & & & & & & & & \\
\hline & $\mathrm{n}$ & 10 & 423 & \multirow{2}{*}{1.00} & & & & & & & & & \\
\hline & BMI $\left[\mathrm{kg} / \mathrm{m}^{2}\right]$ (SE) & $25.8(2.6)$ & $25.3(5.4)$ & & & & & & & & & & \\
\hline & $r s 2071023$ & CC & G-allele & p-value $\$$ & $\mathrm{CC}$ & G-allele & p-value & $\mathrm{CC}$ & G-allele & p-value & CC & G-allele & p-value \\
\hline & $n$ & 143 & 333 & \multirow{2}{*}{0.018} & 39 & 128 & 019 & 49 & 132 & 0,0 & 287 & 722 & ?ח \\
\hline & $\mathrm{BMI}\left[\mathrm{kg} / \mathrm{m}^{2}\right]$ (SE) & $24.5(0.5)$ & $25.7(0.3)$ & & $27.5(0.7)$ & $28.3(0.5)$ & 0.41 & $26.9(0.7)$ & $27.3(0.5)$ & 0.88 & $25.3(0.3)$ & $26.4(0.2)$ & 0.003 \\
\hline
\end{tabular}

\# For current BMI, only significant findings in the discovery sample were further tested for replication. The same SNPs were also tested for replication at the baseline BMI.

* Only patients treated for up to 24 months.

$\$$ p-corrected value for the discovery sample. 
Figure S-1: Pairwise linkage disequilibrium (LD) in CEU HapMap samples for PCK1 polmorphisms. LD expressed as $\mathbf{r}^{2}$.

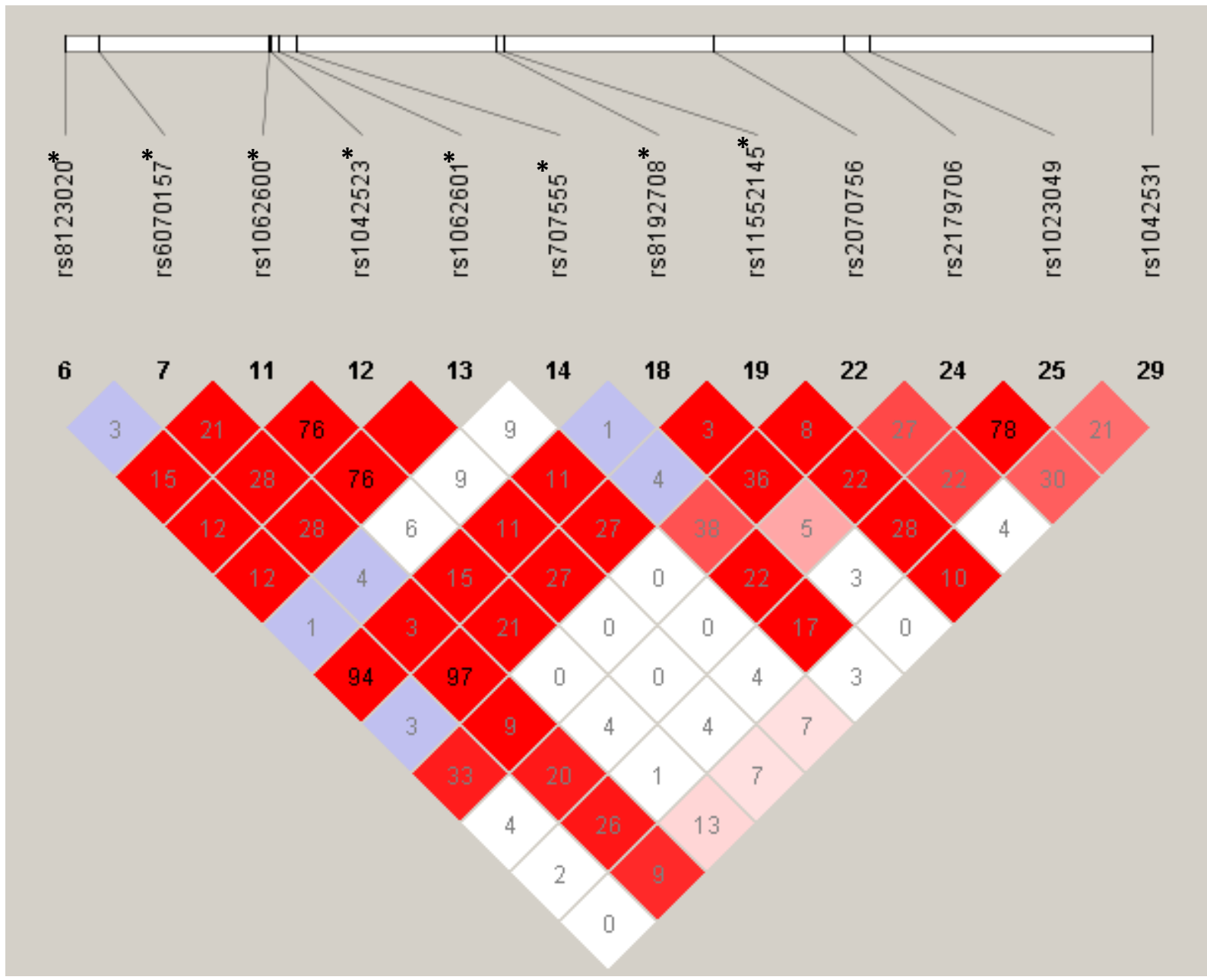

* SNPs tested in the present study, including SNPs in LD with one of the four analyzed SNPs. rs2071023 (not present in the figure) is in LD with $r s 1062600\left(r^{2}=1\right), r s 1062601\left(r^{2}=0.81\right)$ and $r s 1042523\left(r^{2}=0.82\right)$. $r s 11552145$ is in LD with $r s 6070157\left(r^{2}=0.97\right)$. rs8123020 is in LD with $r s 8192708\left(r^{2}=0.94\right)$. 